\title{
WILEY-VCH
}

DOI: 10.1002/ ((please add manuscript number))

Article type: Full Paper

\section{Tunable Photodynamic Switching of DArE@PAF-1 for Carbon Capture}

Richelle Lyndon, Kristina Konstas, Daniel J. Keddie, Matthew R. Hill* and Bradley P. Ladewig*

R. Lyndon, Associate Professor B.P. Ladewig*

Department of Chemical Engineering, Monash University, VIC 3800 (Australia)

E-mail: bradley.ladewig@monash.edu

R. Lyndon, Dr K. Konstas, Dr M. R. Hill*

CSIRO Division of Materials Science and Engineering

Private Bag 33, Clayton South MDC, VIC 3169 (Australia)

E-mail: matthew.hill@csiro.au

Dr D. J. Keddie

Department of Chemistry, School of Science and Technology, University of New England, NSW 2351 (Australia)

Associate Professor B. P. Ladewig

Department of Chemical Engineering, Imperial College London, Exhibition Road, London SW7 2AZ (United Kingdom)

Keywords: metal organic frameworks, porous aromatic frameworks, carbon dioxide capture, photodynamic switching

\section{Abstract}

A new type of photodynamic carbon capture material with up to $26 \mathrm{wt} \% \mathrm{CO}_{2}$ desorption capacity is synthesized via incorporation of diarylethene (DArE) as guest molecules in Porous Aromatic Framework-1 (PAF-1). In these host-guest complexes, the carboxylic acid groups featured in DArE allow multiple non-covalent interactions to exist. DArE loadings ranging from $1-50$ wt $\%$ are incorporated in PAF-1 and the complexes characterized by UV-VIS spectroscopy, FT-IR spectroscopy, $\mathrm{CO}_{2}$ and $\mathrm{N}_{2}$ adsorption. Successful inclusion of DArE in PAF-1 is indicated by the reduction of pore size distributions, and an optimum loading of 5 $\mathrm{wt} \%$ is determined by comparing the percentage photoresponse and $\mathrm{CO}_{2}$ uptake capacity at 1 


\section{WILEY-VCH}

bar. Mechanistic studies suggest that photoswitching modulates the binding affinity between DArE and $\mathrm{CO}_{2}$ towards the host, triggering carbon capture and release. This is the first known example of photodynamic carbon capture and release in a PAF.

\section{Introduction}

In recent years, photodynamic switching has proven to be promising for low cost carbon capture and release, as reported for the first time in our previous study. ${ }^{[1]}$ Light is an attractive stimulus for triggering the capture and release of $\mathrm{CO}_{2}$, owing to its natural abundance and capability for instantaneous delivery into materials. Harnessing light in this manner could potentially overcome the challenges encountered in conventional carbon capture technologies, where energy intensive vacuum, pressure or temperature swings were used to trigger the $\mathrm{CO}_{2}$ release in order to regenerate the absorbents for the subsequent cycle. Previous reports have shown that light responsive properties can be introduced in porous materials through the use of light responsive pendant groups or guest molecules. ${ }^{[2]}$ More recently, localised bending of photoresponsive linkers within the framework can also display photoresponse properties, where photoresponsive linkers integrated within the metal organic framework were used to trigger $\mathrm{CO}_{2}$ release, in which $64 \%$ desorption capacity was obtained under dynamic conditions. ${ }^{[1]}$ More recently still, $76 \%$ desorption capacity was observed under dynamic conditions. ${ }^{[3]}$ Thus, dynamic photoswitching is highly attractive for the efficient capture and release of $\mathrm{CO}_{2}$, whilst lowering the energy required for adsorbent regeneration.

Porous materials remain one of the most intensively studied classes of adsorbents for gas storage and separation applications. ${ }^{[4]}$ Thus, they are the ideal candidates for developing light responsive materials for carbon capture. Porous aromatic frameworks (PAFs) are one of the most promising recent developments in the field of carbon capture materials. ${ }^{[5]}$ PAFs possess many of the inherent properties displayed in metal organic frameworks (MOFs) such as; high surface area, high gas selectivity, high porosity, high gas uptake capability and tunable 


\section{WILEY-VCH}

properties. ${ }^{[6,7,8,9]}$ PAF-1, being one of the most porous versions of the PAF materials, can display BET surface areas of up to $5600 \mathrm{~m}^{2} / \mathrm{g} .{ }^{[7]}$ Furthermore, unlike most MOF-based materials, PAFs have the additional advantage of exhibiting high thermal and hydrothermal stability. ${ }^{[8,9]}$ Recent literature reports showed that optical properties could be introduced in PAFs through the use of photoresponsive pendant groups and photoresponsive linker molecules. ${ }^{[10]}$ However, to this date, dynamic photoresponsive PAF materials for $\mathrm{CO}_{2}$ adsorption have not yet been reported. Thus further research was conducted in order to achieve dynamic photoswitching of PAFs containing light responsive groups for carbon capture.

Amongst the various photochromic molecules, diarylethenes (DArE) are well known photochromic $\pi$-conjugated organic molecules. ${ }^{[11]}$ They contain two aromatic groups that are double bonded together through an alkene linkage. The photoswitching mechanism involves the cyclization of the open-ring and cycloreversion of the closed-ring isomers, following irradiation with UV and visible light respectively. ${ }^{[12,13]}$ The photoresponse property of DArE derivatives are influenced by the conformation of their open-ring isomers, their substituents, conjugation length of the heteroaryl groups and the nature of the ethene bridge. ${ }^{[14]}$ Thus upon ring-closing, the colour generally changes from colourless to a wide range of colouration. ${ }^{[12]}$ The absorption band of the closed isomers in the visible region is due to the strongly conjugated system of the whole molecule, in which it can be further red-shifted by extending the conjugation length using various substituents such as long polyene chain, aryl groups and substituents attached in the 5-position of the thiophene rings. ${ }^{[15,16]}$ Amongst DArE derivatives, dithienylperfluorocyclopentene-based DArEs are attractive guest molecules for photoswitching application due to their high sensitivity, fatigue resistance with respect to repeated switching cycles and thermal stability. ${ }^{[12,16,17,18,19]}$ The open ring isomer displays free rotation at the ethene and aryl groups, in which the two conformations, parallel and antiparallel forms exist and can exchange between each other, even at room temperature. ${ }^{[20,21]}$ 


\section{WILEY-VCH}

However, photocyclization can only proceed through the antiparallel conformation. ${ }^{[22-24]}$

Chemically gated photochromism can be introduced through the preparation of DArE derivatives with interlocking arms, such as those with carboxylic acid groups or mercaptoalkyl groups at the external positions of the heterocyclic rings. ${ }^{[23]}$ This would effectively lock the molecule in the non-photoactive parallel form. Upon disruption of the hydrogen bonds or disulfide linkages, the molecules can isomerize back to the antiparallel form, regaining its photoactivity. Thus, gated photochromism could modulate the binding affinity of host-guest systems. It has been shown that photoresponse can be achieved through the incorporation of diarylethene inside adsorbents. ${ }^{[3,25]}$

a)

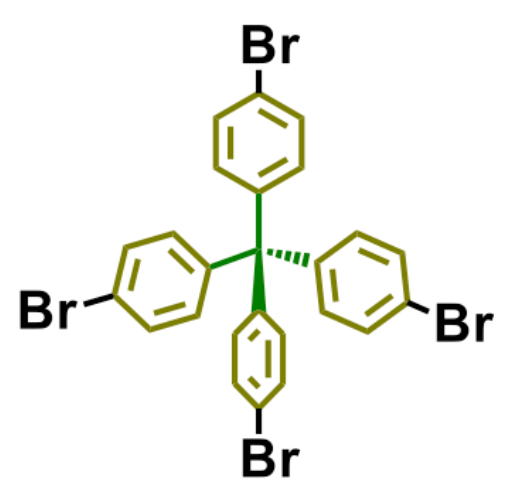

1. $\mathrm{Ni}(\mathrm{COD})_{2}$

2. O-DArE

3. $\mathrm{CO}_{2}$

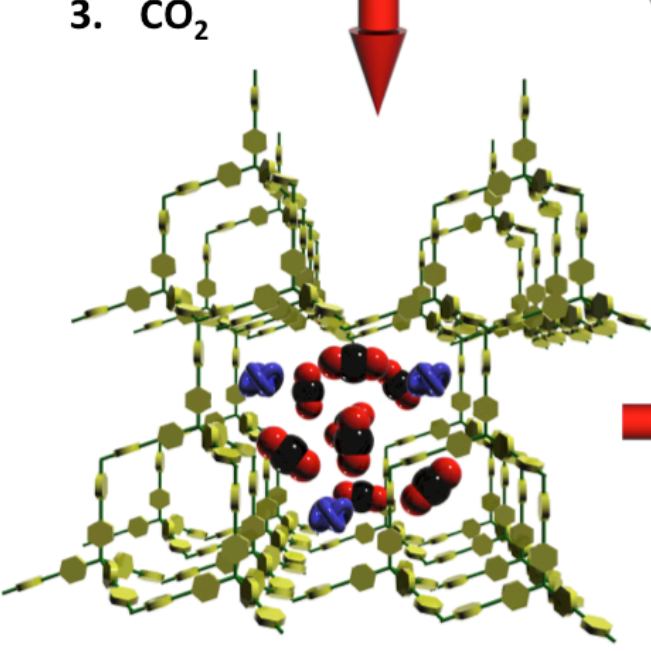

o-DArE @PAF-1 b)
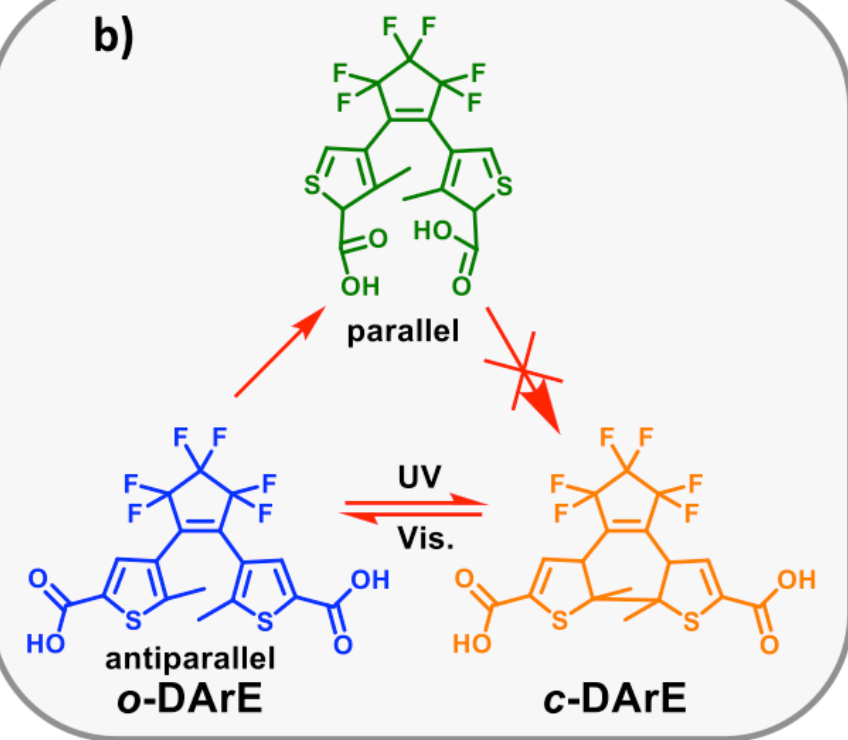

hv

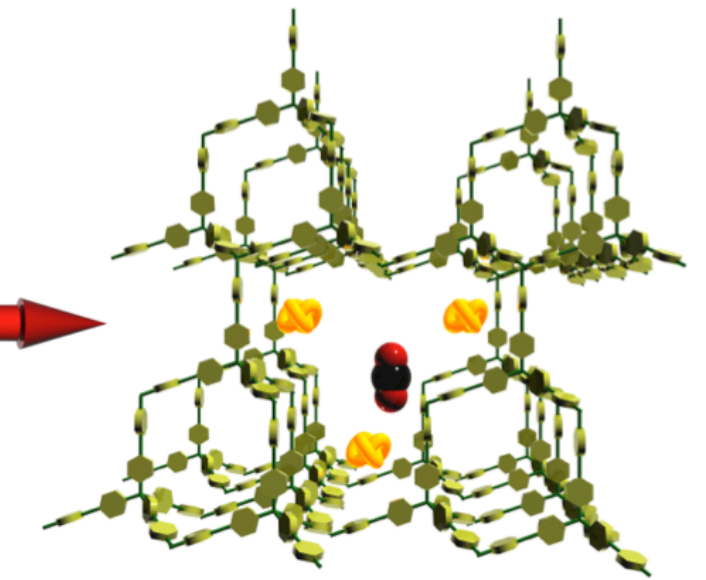

c-DArE @PAF-1 


\section{WILEY-VCH}

Figure 1. Dynamic photoswitching of light responsive DArE@PAF-1. Broadband light irradiation of the material resulted in a spontaneous $\mathrm{CO}_{2}$ release. (a) PAF-1 is produced by a self-condensation of tetraphenylbromomethane (top left), which is then loaded with the diarylethene dye $o$-DArE (bottom left), which induces the release of adsorbed $\mathrm{CO}_{2}$ upon exposure to visible light (bottom right). (b) The dye undergoes a reversible cyclization reaction which activates the $\mathrm{PAF}$ pores.

In this work, dithienylperfluorocyclopentene based DArE bearing carboxyl groups was chosen as the guest molecule for PAF-1. The presence of long $\pi$-conjugation length and interlocking arms could potentially offer multi non-covalent interactions in the host-guest complex, thereby affecting the photoswitching capabilities upon gas adsorption.

Herein we report PAF-1 containing photoresponsive DArE guest molecules exhibits dynamic $\mathrm{CO}_{2}$ capture and release properties upon broadband light irradiation (Figure 1). The inclusion of DArE guest molecules allows the host-guest complex to display up to $26 \mathrm{wt} \%$ desorption capacity at $50 \mathrm{wt} \%$ DArE loading. The observed photodynamicity was due to host-guest competition between DArE and $\mathrm{CO}_{2}$ inside the sterically hindered pores of the PAF.

Furthermore, the presence of carboxyl groups in DArE, along with the aromatic nature of the host and guest molecules, allowed multi non-covalent interactions (e.g., hydrogen bonding, aromatic interaction) upon light irradiation. ${ }^{[26-29]}$

\section{Results and Discussion}

\section{1. $\mathrm{N}_{2}$ Adsorption Isotherm Measurement}

The successful inclusion of DArE molecules in PAF-1 was first suggested by the decrease in $\mathrm{N}_{2}$ adsorption capacity, as shown in Figure 2a. In its natural state, DArE displays an openring structure, with a molecular diameter of $0.9-1.3 \mathrm{~nm}$. The pore size distribution calculated from the $\mathrm{N}_{2}$ adsorption isotherm at $77 \mathrm{~K}$ indicated that PAF-1 had a pore width in the range of $1.2-3.0 \mathrm{~nm}$, with the majority of surface area arising from pores in the range $1.2-1.7 \mathrm{~nm}$, as shown in Figure 2b. Further analyses of the isotherm supported the result, indicated by the decrease in pore size distribution intensities (Figure 2b), surface areas (Figure 2c) and total 


\section{WILEY-VCH}

pore volume (Figure 2d) as the DrAE loading increased from $1-50 \mathrm{wt} \% .^{[12]}$ The result was expected as it indicated that the guest molecules progressively occupied more of the vacant sites within the PAF-1.
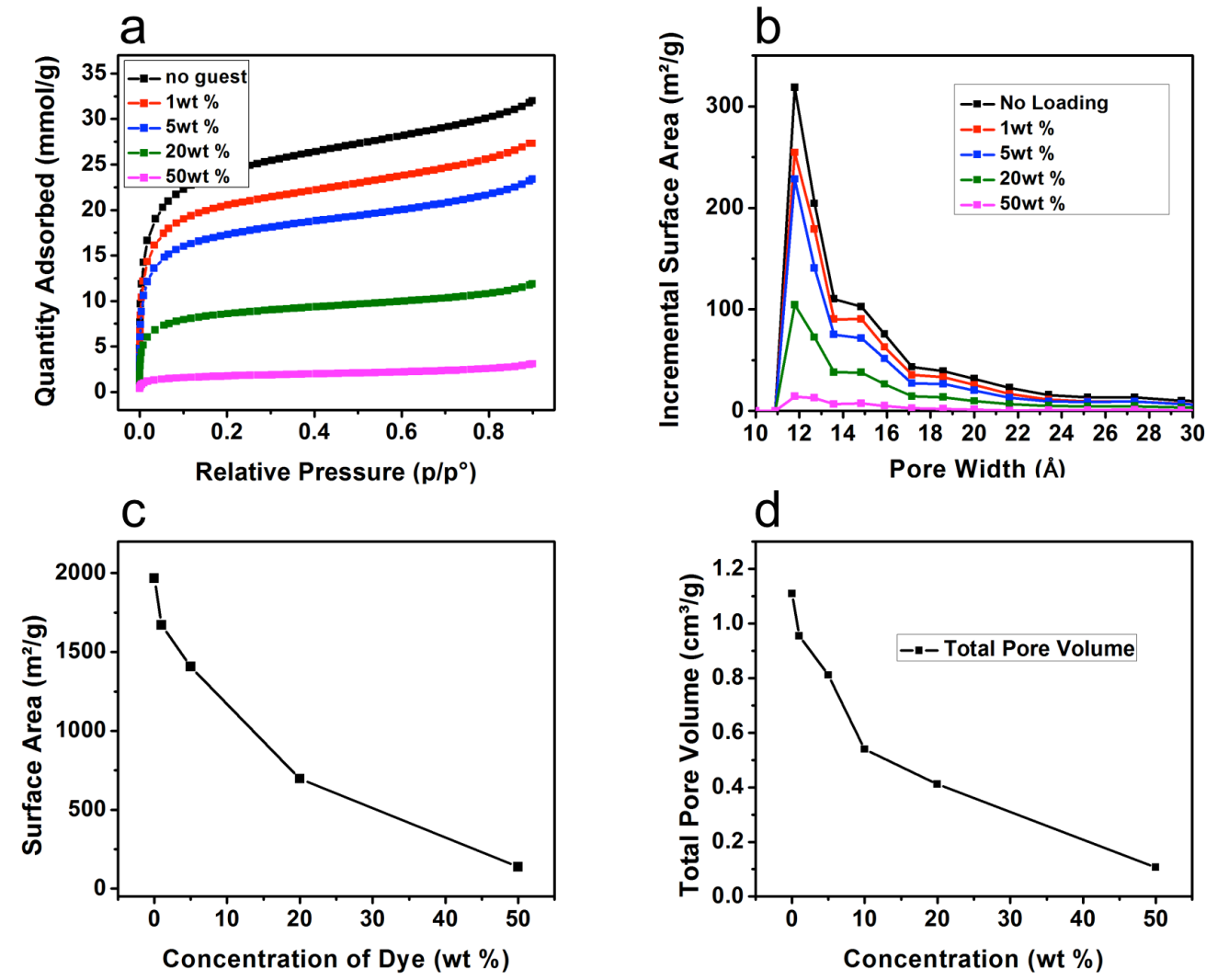

Figure 2. $\mathrm{N}_{2}$ adsorption isotherm of PAF-1 (black) and DArE@PAF-1 (1wt\%, red; 5wt \%, blue; $20 \mathrm{wt} \%$, green; $50 \mathrm{wt} \%$, magenta) at $77 \mathrm{~K}$ (a), showing the effects of DArE loading on the pore size distributions (b), BET surface areas (c), and total pore volumes (d) of PAF-1.

\subsection{Carbon Capture and Release Under Dynamic Photoswitching Conditions}

To examine the potential of dynamic carbon capture and release in DArE@PAF-1, a

photoswitching experiment was conducted at room temperature with $\mathrm{CO}_{2}$, the results of which are presented in Figure 3. 

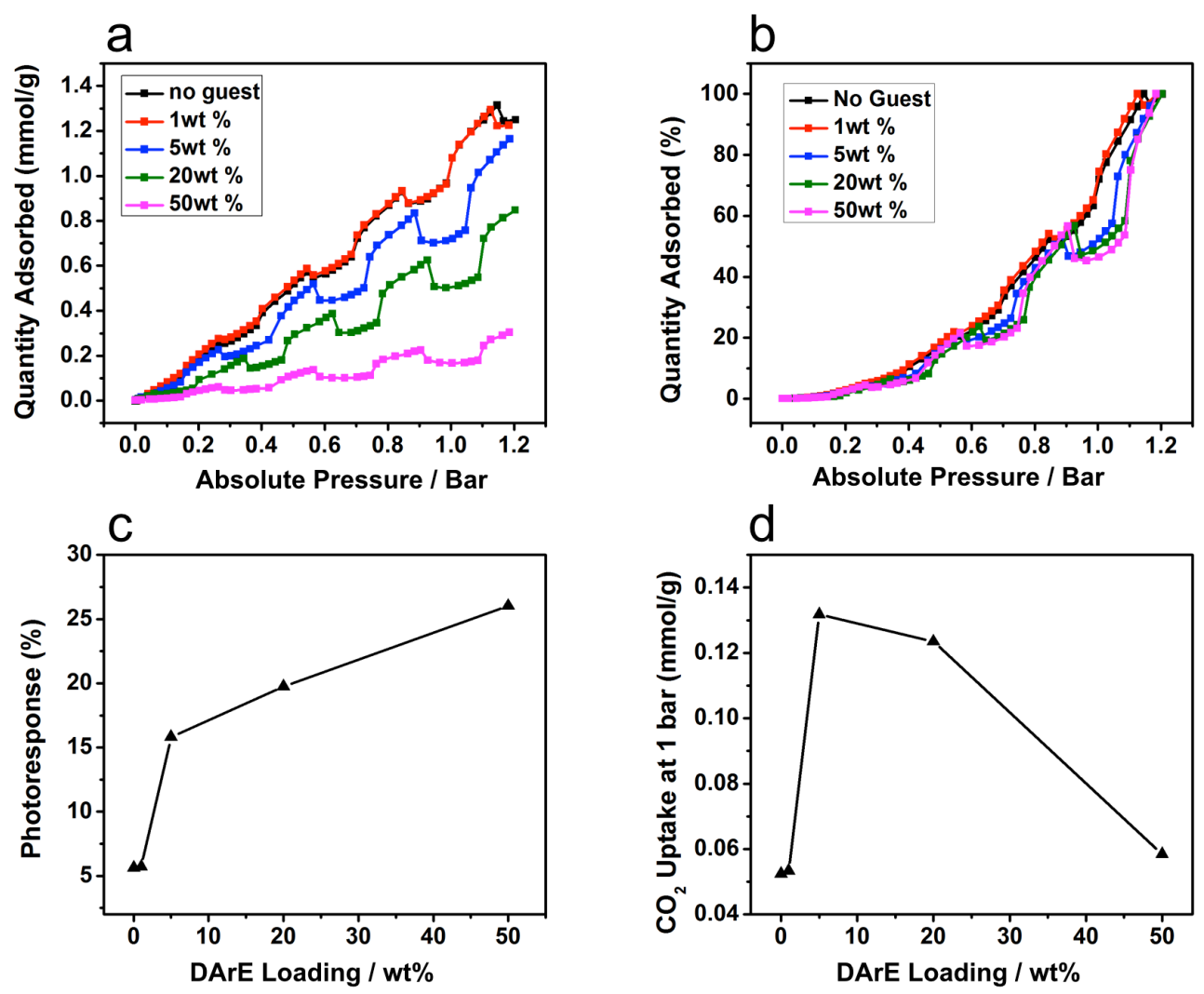

Figure 3. $\mathrm{CO}_{2}$ adsorption isotherms of PAF-1 and DArE@PAF-1 at $303 \mathrm{~K}$ under photoswitching conditions showed that $\mathrm{CO}_{2}$ capture and release occurred reversibly in the absence and presence of light respectively (a), $\mathrm{CO}_{2}$ sorption isotherms were normalised for clarity, showing that greater photoresponse was obtained with higher DArE loading (b), tradeoff between photoresponse (c), and $\mathrm{CO}_{2}$ uptake capacity at 1 bar (d). Photoswitching occurs approximately every 15 minutes to allow clear detection of $\mathrm{CO}_{2}$ capture and release. Photoresponse effect can be observed within 1-2 minutes.

The observed photoresponse was similar to our recent study, ${ }^{[1]}$ as $\mathrm{CO}_{2}$ capture and release occurred reversibly in the absence and presence of light respectively. The adsorption isotherm obtained under static irradiation matched those irradiated parts of the isotherm obtained under dynamic conditions (Figure S1). Such dynamicity was likely due to the presence of DArE molecules in the PAF, in which the intermolecular interactions between $\mathrm{CO}_{2}$ molecules and the adsorption sites occurred, triggering instantaneous $\mathrm{CO}_{2}$ release. ${ }^{[1,26,27,30,31]}$ However, it was found that with varying DArE loading, there was a trade-off between photoresponse (Figure 3c) and $\mathrm{CO}_{2}$ uptake capacity. To correlate photoactivity and $\mathrm{CO}_{2}$ adsorption, $\mathrm{CO}_{2}$ 


\section{WILEY-VCH}

uptake capacity at 1 bar, which showed the largest photoresponse, was calculated and compared (Figure 3d). When not irradiated, the $\mathrm{CO}_{2}$ uptake capacity increased at higher loading concentration, but reduced when the loading concentration exceeded $5 \mathrm{wt} \%$, indicating an optimal loading concentration. This suggested competitive interactions between DArE and $\mathrm{CO}_{2}$ with the host, preventing $\mathrm{CO}_{2}$ from occupying the adsorption sites. The increase in dynamic photoresponse during the $\mathrm{CO}_{2}$ adsorption measurement with higher DArE loading concentrations corresponded to the increase in photoactivity of DArE in PAF1 (Figure 3c). Furthermore, $\mathrm{CO}_{2}$ adsorption in the presence of light did not follow the Dubinin-Radushkevich (D-R) model and the change in pore size could not be determined (Figure S3). This was due to gas adsorption at the surface being disturbed by the presence of UV light. ${ }^{[32]}$ A photoswitching experiment was also performed on unloaded PAF-1 as a control study to ensure that the photodynamicity was mainly due to the presence of DArE molecules (Figure 3a). The low photoresponse exhibited by PAF-1 was due to the aromatic nature of its framework.
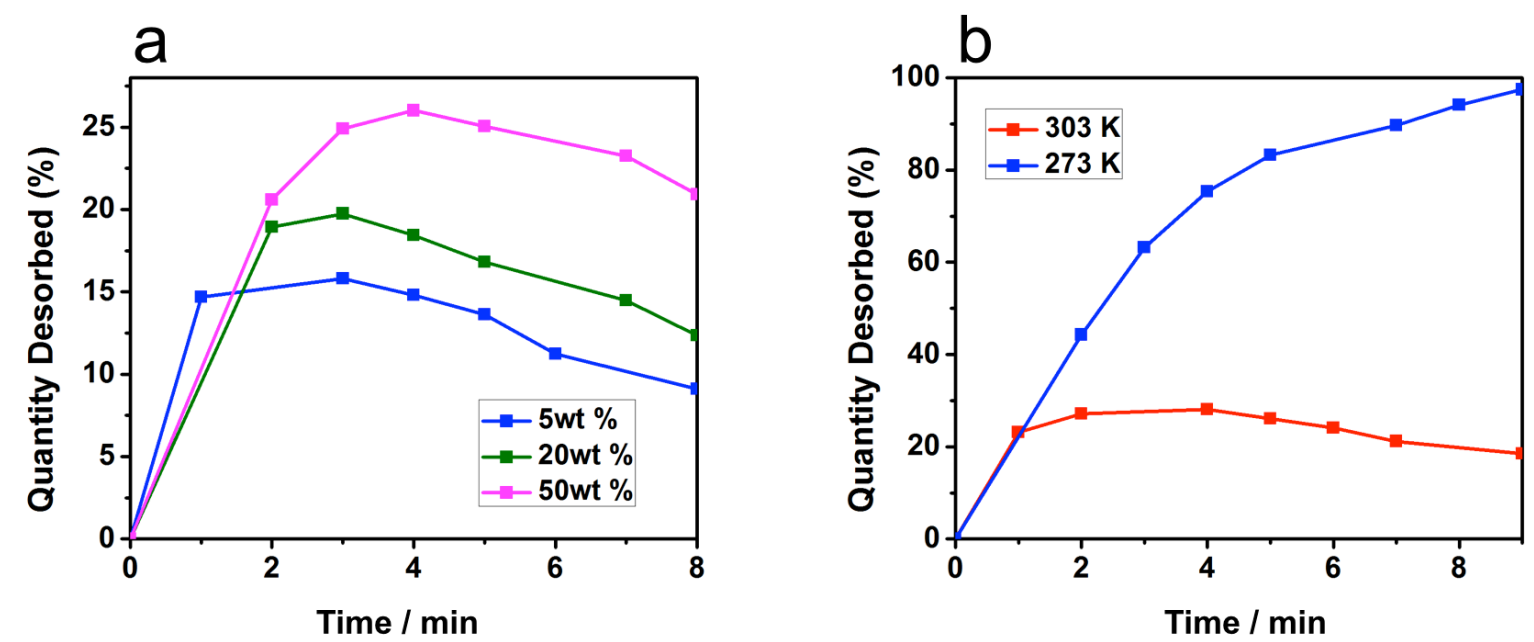

Figure 3. Kinetic studies of $\mathrm{CO}_{2}$ desorption at $303 \mathrm{~K}$ and $273 \mathrm{~K}$ at a pressure range of $0.6-1$ bar, showing the effects of different DArE loadings (a) and temperature with $50 \mathrm{wt} \%$ DArE@PAF-1 (b).

Adsorption kinetic studies showed that desorption capacities at 1 bar can increase by $65 \%$ from $5 \mathrm{wt} \%$ to $50 \mathrm{wt} \%$ within 4 minutes of light irradiation (Figure 4). Some $\mathrm{CO}_{2}$ was re- 


\section{WILEY-VCH}

adsorbed beyond this point, indicating that perhaps there was a small shift in the equilibrium, resulting in a slight preferential binding of $\mathrm{CO}_{2}$ with the host. However, the equilibrium was shifted significantly towards DArE-PAF-1 interactions at lower temperature, resulting in a complete $\mathrm{CO}_{2}$ desorption within 9 minutes of irradiation (Figure 4b).

\subsection{Photoswitching Mechanism Studied Using Solid-State UV-Vis and FT-IR}

Further photoresponse studies were conducted to assess the dynamic properties of PAF-1 during dynamic gas adsorption. Solid-state UV-VIS and FT-IR revealed the possible photoswitching mechanism. Upon UV (340 nm) and visible (480 nm) excitation of the free DArE molecule, absorption peaks which correspond to the closed-ring (c-DArE) and openring DArE (o-DArE) at 460 and $580 \mathrm{~nm}$, and $370 \mathrm{~nm}$ respectively were observed (Figure $\mathrm{X}) .{ }^{[19,33]}$ These peaks were also observed in the sample prepared, confirming the presence of DArE within PAF-1 (Figure S4). To further analyse the photoresponse mechanism, the peak intensities at 460 and 370 nm exhibited by the free DArE and DArE@PAF-1 during UV-VIS experiments were monitored by continually irradiating the materials with alternating UV and visible light. From the result, the peak intensities of $\boldsymbol{c}$-DArE@PAF-1 at $460 \mathrm{~nm}$ remained constant, whereas the peak intensities of $\boldsymbol{o - D A r E @ P A F - 1 ~ a t ~} 370 \mathrm{~nm}$ gradually decreased over several cycles (Figure S4f). Similar trends were observed in the free o-DArE molecule (Figure S4e). The slight decrease in peak intensities at $370 \mathrm{~nm}$ indicated that perhaps photocyclization was inhibited. 
WILEY-VCH

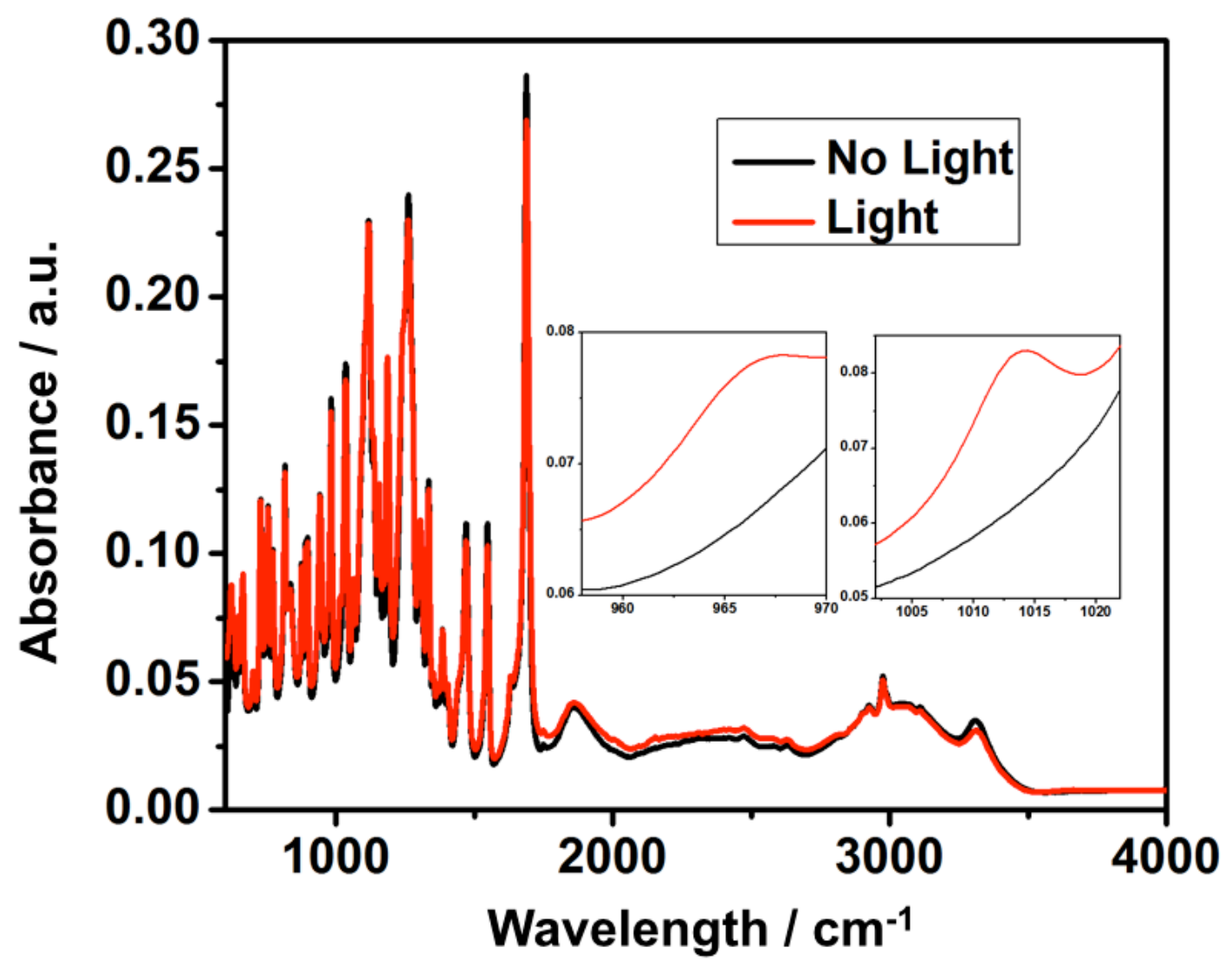

Figure 5. Full FT-IR spectra of DArE in the absence (black) and presence (red) of light irradiation.

FT-IR results revealed the photoisomerization behaviours of DArE@PAF-1 in more detail. Upon light irradiation, the FT-IR spectrum of host-free DArE showed that the photogeneration of the closed ring isomer can be detected by the formation of 2 additional weak C-F absorption bands at 966 and $1013 \mathrm{~cm}^{-1}$ (Figure 5). ${ }^{[34]}$ However, these two signals were not observed in the FT-IR spectrum of DArE@PAF-1 (Figure 6). 


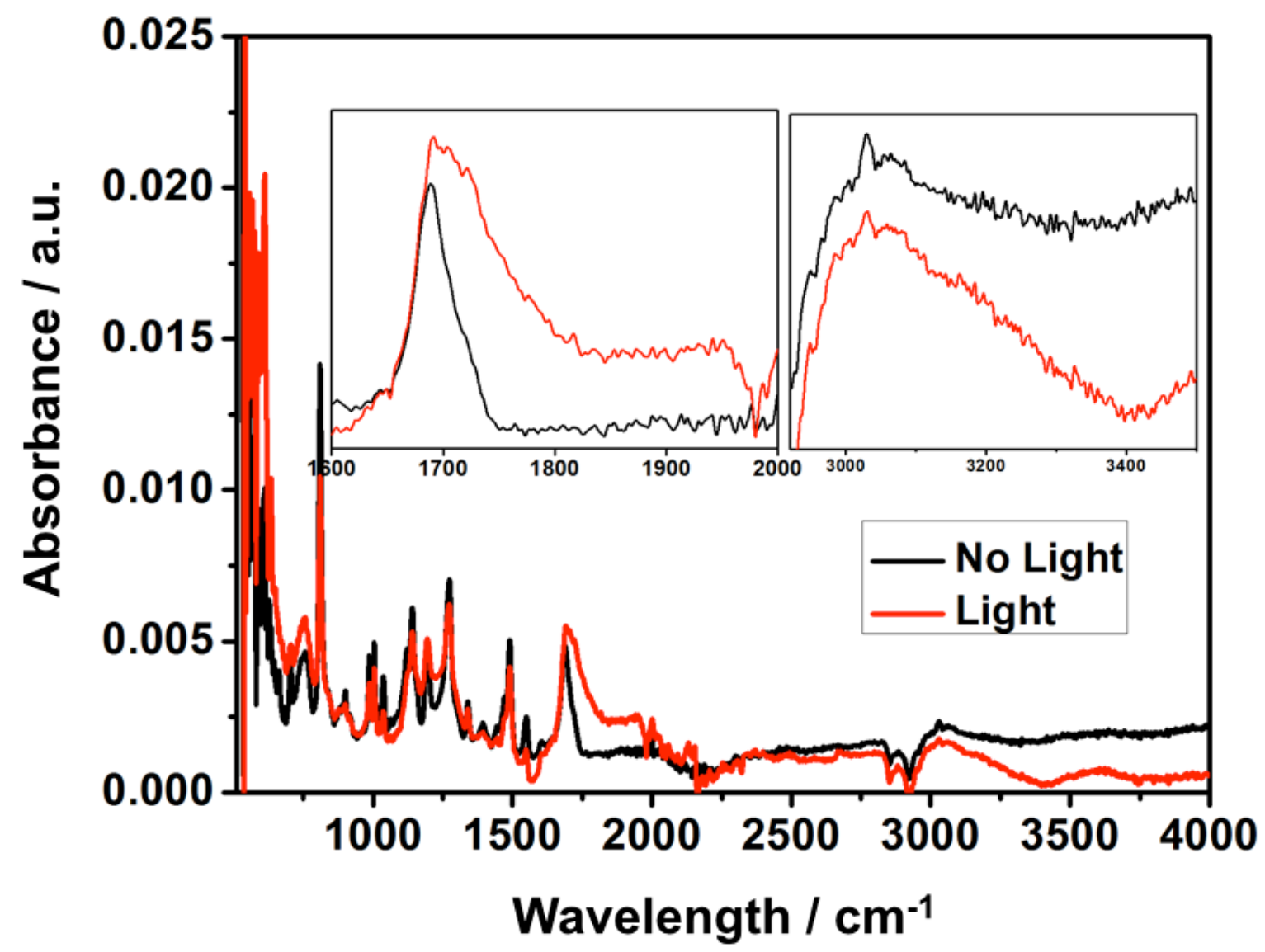

Figure 6. Full FT-IR spectra of DArE@PAF-1 in the absence (black) and presence (red) of light irradiation.

This may be due to the peaks associated with DArE photoresponse being too weak to be detected and had been masked by the PAF's peaks. Instead, the $\mathrm{C}=\mathrm{O}\left(1688 \mathrm{~cm}^{-1}\right)$ and $\mathrm{O}-\mathrm{H}$ $\left(3000 \mathrm{~cm}^{-1}\right)$ peaks showed considerable broadening, suggesting that multiple intermolecular non-covalent interactions may be involved. ${ }^{[35]}$ Upon light irradiation, the formation of $c$ DArE exhibited a planar geometry which is less bulky compared to its twisted open structure. ${ }^{[29,31,36]}$ Thus aryl-perfluoaryl interactions became more favourable between the guest molecules and the host, and hence the peak broadening at $1688 \mathrm{~cm}^{-1} \cdot{ }^{[26-28,30]}$ With the aromatic stacking occurring, the movements due to photocyclization upon light irradiation would be suppressed. This was also confirmed in FT-IR spectra of irradiated DArE@PAF-1 and free DArE, as shown by the reduction in peak intensities at 810, 985, 1035, 1140 and $1548 \mathrm{~cm}^{-1}$ regions (Figure 5 and Figure 6). These peaks correspond to the vibration modes 


\section{WILEY-VCH}

of the thiophene and cyclopentene groups in DArE. ${ }^{[34,37]}$ The reduction in peak intensities was due to the loss of aromatic character of two thiophene rings in DArE upon ring closure. ${ }^{[18,}$ ${ }^{38]}$ Furthermore, the restricted movement of DArE guest molecules inside the pores of PAF-1 also enhanced the ring bending vibration of the aryl and ethene groups around 500-600 cm-1 region (Figure 6). ${ }^{[21,39]}$ In conjunction with the aromatic stacking, H-bonding was also detected at $3000 \mathrm{~cm}^{-1}{ }^{[26]}$ This was only observed in the FT-IR spectra of DArE@PAF-1, which suggested the formation of the parallel $\boldsymbol{o}$-DArE conformer, where intramolecular Hbonding between the carboxylic acid of the guest molecules may occur (shown in Figure S5), a known phenomenon reported in the literature. ${ }^{[21-23]}$ The stable intramolecular H-bonds are unlikely to be broken without H-bond breaking agents. ${ }^{[21-23]}$ As DArE can exist in three conformers, the antiparallel $\boldsymbol{o}$-DArE (Figure S6) and $\boldsymbol{c}$-DArE conformers (Figure S7) may interconvert reversibly under broadband light irradiation, but some parallel $\boldsymbol{o}$-DArE conformers may form in the process. ${ }^{[22,23,40]}$

The formation of the parallel conformer prevented photocyclization back to its antiparallel form. ${ }^{[22,23,40]}$ This would explain the incomplete ring opening process suggested in solid UVVIS result (Figure S4). Thus, the presence of multiple interactions in light irradiated DArE@PAF-1 may be responsible for triggering spontaneous $\mathrm{CO}_{2}$ release. The competitive interaction between DArE and $\mathrm{CO}_{2}$ molecules with the host would occur as adsorption took place within a sterically demanding environment. ${ }^{[26-28,30]}$

\section{Conclusion}

Photodynamic $\mathrm{CO}_{2}$ capture and release from PAF containing photoactive guest molecules has been demonstrated for the first time. Light can be switched on and off to trigger $\mathrm{CO}_{2}$ desorption and adsorption respectively. Such dynamicity is likely due to the increase in hostguest interactions upon the formation of the parallel $\boldsymbol{o}$-DArE conformer, as shown in the UVVIS and FT-IR results. During photoirradiation, aromatic stacking and H-bonding occurred, 


\section{WILEY-VCH}

resulting in the inhibition of DArE photocylisation in a sterically hindered environment. Thus, it promoted the formation of its parallel $\boldsymbol{o}$-DArE conformer, featuring interlocking arms due to H-bonding interactions. The PAF-1-DArE and $\mathrm{CO}_{2}$-PAF-1 interactions compete with each other, weakening the intermolecular interactions between $\mathrm{CO}_{2}$ molecules and the adsorption sites, triggering instantaneous $\mathrm{CO}_{2}$ release. The results of this study also demonstrate the level of photoresponse can be modulated through the use of different DArE loadings. A stronger photoresponse, of up to $26 \%$, can be obtained at higher loadings (50 wt \%), but beyond the optimum concentration of $5 \mathrm{wt} \%$, the $\mathrm{CO}_{2}$ uptake capacity gradually reduced. The ability to modulate the photoresponse could offer greater control for carbon capture and release in industrial applications.

\section{Experimental Section}

Materials: DArE from was prepared by adaption of relevant literature procedures ${ }^{[41]}$ (for experimental details see Supporting Information). PAF-1 was prepared as per the published literature method. ${ }^{[9]}$

Preparation of DArE@PAF-1: Different concentrations of DArE were loaded in PAF-1 (weight percentage diarylethene loading) in $\sim 5 \mathrm{~mL}$ dry diethyl ether in Quartz ASAP tube. The solution was sonicated for $1 \mathrm{~h}$ to allow even loading distribution within the PAF. The solvent was then evaporated under $\mathrm{N}_{2}$ atmosphere.

UV-VIS Spectroscopy: UV-VIS spectra were obtained using FlexStation ${ }^{\circledR} 3$ Benchtop MultiMode Microplate Reader. The solid samples used were activated accordingly prior to measurements. Excitation and emission wavelengths of the sample in solid state were read in a Corning black flat clear bottom microplate in fluorescence reading mode at room temperature. For photoresponse analyses, the sample was irradiated with light for a certain period of time and the spectra were recorded immediately after irradiation. 


\section{WILEY-VCH}

FT-IR Spectroscopy: Infrared spectra were obtained on Thermoscientific Nicolet 6700 in powder form using the attenuated total reflectance method (ATR). Time-resolved photoresponse experiments were conducted by irradiating the solid sample for a certain period of time and the spectra were recorded immediately after or during irradiation. The solid samples used were activated accordingly prior to measurements.

Gas Adsorption: $\mathrm{N}_{2}$ and $\mathrm{CO}_{2}$ adsorption isotherms of samples were recorded at low pressure (0-1.2 bar) by a volumetric method using Micromeritics ASAP 2420 or Tristar II 3020 instruments respectively. Prior to measurement, the sample was activated under vacuum and heat. The sample was activated at $150{ }^{\circ} \mathrm{C}$ under dynamic vacuum at $10^{-6}$ Torr for a certain period of time to remove any solvent molecules. Approximately $100 \mathrm{mg}$ of dried activated sample was weighed in a pre-dried and weighed ASAP tube. Multiple replicate weights of the activated sample were taken and an average weight was calculated for both the empty tube and the added sample. Quartz ASAP tubes were used for experiments involving UV light and glass ASAP tubes were used for visible light switching experiments. An accurate weight of the degassed sample was calculated prior to analysis. Gas adsorption measurements were performed using ultra-high purity $(99.999 \%) \mathrm{CO}_{2}$ and $\mathrm{N}_{2}$ gas. Pre-weighed and dried custom made aluminium foiled quartz or glass ASAP tube was used for light switching experiments. A custom made light cell was used to contain the BET tube and light guide to allow maximum light exposure and coverage on the sample when the light was switched on. A Cole Palmer Model BT 15 heated circulating bath was used to maintain the temperature at $303 \mathrm{~K}$ or $273 \mathrm{~K}$ throughout the experiment. A temperature probe was wedged inside the light cell between the ASAP tube and light guide to monitor the temperature.

Photoresponse Studies: Acticure ${ }^{\circledR} 4000$ containing a high pressure 100 Watt mercury vapour short arc lamp was used as a UV-VIS light source to trigger the sample's light response during analysis. The light was fixed at the highest intensity output with no filter (200-500 nm, corresponding to $24,600 \mathrm{~mW} / \mathrm{cm}^{2}$ ). 


\section{WILEY-VCH}

\section{Supporting Information}

Supporting Information is available from the Wiley Online Library or from the author.

\section{Acknowledgements}

This research is supported by the Science and Industry Endowment Fund.

Received: ((will be filled in by the editorial staff))

Revised: ((will be filled in by the editorial staff))

Published online: ((will be filled in by the editorial staff))

[1] R. Lyndon, K. Konstas, B. P. Ladewig, P. D. Southon, P. C. J. Kepert, M. R. Hill, Angewandte Chemie International Edition 2013, 52, 3695.

[2] N. Yanai, T. Uemura, M. Inoue, R. Matsuda, T. Fukushima, M. Tsujimoto, S. Isoda, S. Kitagawa, Journal of the American Chemical Society 2012, 134, 4501.

[3] F. Luo, C. B. Fan, M. B. Luo, X. L. Wu, Y. Zhu, S. Z. Pu, W. Y. Xu, G. C. Guo, Angewandte Chemie International Edition 2014, 53, 9298.

[4] D. M. D'Alessandro, T. McDonald, Pure and Applied Chemistry 2011, 83, 57; D. M.

D'Alessandro, B. Smit, J. R. Long, Angewandte Chemie International Edition 2010, 49, 6058;

M. E. Davis, Nature 2002, 417, 813.

[5] S. J. Garibay, M. H. Weston, J. E. Mondloch, Y. J. Colon, O. K. Farha, J. T. Hupp, S. T. Nguyen, CrystEngComm 2013, 15, 1515.

[6] J.-R. Li, R. J. Kuppler, H.-C. Zhou, Chemical Society Reviews 2009, 38, 1477; S. Ma, H.-C. Zhou, Chemical Communications 2010, 46, 44; S. Ma, D. Sun, J. M. Simmons, C. D. Collier, D. Yuan, H.-C. Zhou, Journal of the American Chemical Society 2008, 130, 1012; Y. Zhu, H. Long, W. Zhang, Chemistry of Materials 2013, 25, 1630.

[7] R. Babarao, S. Dai, D.-e. Jiang, Langmuir 2011, 27, 3451. 


\section{WILEY-VCH}

[8] T. Ben, S. Qiu, CrystEngComm 2013, 15, 17; T. Ben, H. Ren, S. Ma, D. Cao, J. Lan, X. Jing, W. Wang, J. Xu, F. Deng, J. M. Simmons, S. Qiu, G. Zhu, Angewandte Chemie International Edition 2009, 48, 9457.

[9] K. Konstas, J. W. Taylor, A. W. Thornton, C. M. Doherty, W. X. Lim, T. J. Bastow, D. F. Kennedy, C. D. Wood, B. J. Cox, J. M. Hill, A. J. Hill, M. R. Hill, Angewandte Chemie International Edition 2012, 51, 6639.

[10] P. K. Kundu, G. L. Olsen, V. Kiss, R. Klajn, Nature Communications 2014, 5; H. A. Patel, S. Hyun Je, J. Park, D. P. Chen, Y. Jung, C. T. Yavuz, A. Coskun, Nature Communications 2013, 4, 1357; Y. Zhu, W. Zhang, Chemical Science 2014, 5, 4957.

[11] K. Matsuda, M. Irie, Journal of Photochemistry and Photobiology, C: Photochemistry Reviews 2004, 5, 169.

[12] M. Irie, Photochemical \& Photobiological Sciences 2010, 9, 1535.

[13] S. Kobatake, Y. Matsumoto, M. Irie, Angewandte Chemie International Edition 2005, 44, 2148; F. Terao, M. Morimoto, M. Irie, Angewandte Chemie International Edition 2012, $51,901$.

[14] K. Yuan, J. Boixel, H. Le Bozec, A. Boucekkine, H. Doucet, V. Guerchais, D. Jacquemin, Chemical Communications 2013, 49, 7896.

[15] S. Castellanos, L. Grubert, R. Stößer, S. Hecht, The Journal of Physical Chemistry C 2013, 117, 23529; J. Ern, A. T. Bens, H.-D. Martin, K. Kuldova, H. P. Trommsdorff, C. Kryschi, The Journal of Physical Chemistry A 2002, 106, 1654; J. Ern, A. T. Bens, H. D. Martin, S. Mukamel, D. Schmid, S. Tretiak, E. Tsiper, C. Kryschi, Chemical Physics 1999, 246, 115; S. L. Gilat, S. H. Kawai, J.-M. Lehn, Chemistry - A European Journal 1995, 1, 275; E. Kim, M. Kim, K. Kim, Bulletin of the Korean Chemical Society 2008, 29, 827; A. Thomas Bens, D. Frewert, K. Kodatis, C. Kryschi, H.-D. Martin, H. P. Trommsdorff, European Journal of Organic Chemistry 1998, 1998, 2333. 


\section{WILEY-VCH}

[16] A. R. Santos, R. Ballardini, P. Belser, M. T. Gandolfi, V. M. Iyer, L. Moggi,

Photochemical \& Photobiological Sciences 2009, 8, 1734.

[17] C. Brieke, F. Rohrbach, A. Gottschalk, G. Mayer, A. Heckel, Angewandte Chemie International Edition 2012, 51, 8446; M. Irie, T. Lifka, S. Kobatake, N. Kato, Journal of the American Chemical Society 2000, 122, 4871; M. Irie, K. Uchida, Bulletin of the Chemical Society of Japan 1998, 71, 985; K. Uchida, T. Matsuoka, S. Kobatake, T. Yamaguchi, M. Irie, Tetrahedron 2001, 57, 4559; J. Yuan, Z. Li, M. Hu, S. Li, S. Huang, J. Yin, S. H. Liu, Photochemical \& Photobiological Sciences 2011, 10, 587.

[18] M. Irie, Chemical Reviews 2000, 100, 1683; M. Irie, M. Mohri, Journal of Organic Chemistry $1988,53,803$.

[19] M. Morimoto, M. Irie, Chemistry - A European Journal 2006, 12, 4275.

[20] H. Tian, S. Yang, Chemical Society Reviews 2004, 33, 85.

[21] C. C. Warford, V. Lemieux, N. R. Branda, in Molecular Switches, Vol. 1 (Eds: B. L. Feringa, W. R. Browne), Wiley-VCH, Weinheim, Germany 2011, 1.

[22] M. Irie, O. Miyatake, K. Uchida, Journal of the American Chemical Society 1992, 114, 8715.

[23] M. Irie, O. Miyatake, R. Sumiya, M. Hanazawa, Y. Horikawa, K. Uchida, Molecular Crystals and Liquid Crystals Science and Technology Section A 1994, 246, 155.

[24] K. Shibata, K. Muto, S. Kobatake, M. Irie, The Journal of Physical Chemistry A 2001, 106, 209.

[25] H. Okada, N. Nakajima, T. Tanaka, M. Iwamoto, Angewandte Chemie 2005, 117, 7399; I. M. Walton, J. M. Cox, J. A. Coppin, C. M. Linderman, D. G. Patel, J. B. Benedict, Chemical Communications 2013, 49, 8012.

[26] M. Morimoto, M. Irie, Chemical Communications 2005, 0, 3895.

[27] M. Morimoto, S. Kobatake, M. Irie, Chemical Record 2004, 4, 23. 


\section{WILEY-VCH}

[28] S. Yagai, K. Ohta, M. Gushiken, K. Iwai, A. Asano, S. Seki, Y. Kikkawa, M.

Morimoto, A. Kitamura, T. Karatsu, Chemistry - A European Journal 2012, 18, 2244.

[29] X. Zhou, Y. Duan, S. Yan, Z. Liu, C. Zhang, L. Yao, G. Cui, Chemical

Communications 2011, 47, 6876.

[30] S. Meejoo, B. M. Kariuki, K. D. M. Harris, ChemPhysChem 2003, 4, 766; M.

Morimoto, S. Kobatake, M. Irie, Photochemical \& Photobiological Sciences 2003, 2, 1088; S. Yagai, K. Iwai, M. Yamauchi, T. Karatsu, A. Kitamura, S. Uemura, M. Morimoto, H. Wang, F. Würthner, Angewandte Chemie International Edition 2014, 53, 2602.

[31] S. Yagai, K. Ishiwatari, X. Lin, T. Karatsu, A. Kitamura, S. Uemura, Chemistry - A European Journal 2013, 19, 6971.

[32] R. K. Motkuri, P. K. Thallapally, S. K. Nune, C. A. Fernandez, B. P. McGrail, J. L. Atwood, Chemical Communications 2011, 47, 7077.

[33] L. N. Lucas, J. J. D. De Jong, J. H. Van Esch, R. M. Kellogg, B. L. Feringa, European Journal of Organic Chemistry 2003, 155.

[34] J. J. D. De Jong, W. R. Browne, M. Walko, L. N. Lucas, L. J. Barrett, J. J. McGarvey, J. H. Van Esch, B. L. Feringa, Organic \& Biomolecular Chemistry 2006, 4, 2387.

[35] L. Ma, Q. Wang, G. Lu, R. Chen, X. Sun, Langmuir 2009, 26, 6702.

[36] T. Hirose, K. Matsuda, M. Irie, Journal of Organic Chemistry 2006, 71, 7499; D.

Kitagawa, H. Nishi, S. Kobatake, Angewandte Chemie International Edition 2013, 52, 9320.

[37] A. Takata, S. Yokojima, H. Nakagawa, Y. Matsuzawa, A. Murakami, S. Nakamura, M. Irie, K. Uchida, Journal of Physical Organic Chemistry 2007, 20, 998.

[38] S. Kobatake, H. Hasegawa, K. Miyamura, Crystal Growth \& Design 2011, 11, 1223.

[39] H. Jean-Ruel, M. Gao, M. A. Kochman, C. Lu, L. C. Liu, R. R. Cooney, C. A.

Morrison, R. J. D. Miller, Journal of Physical Chemistry B 2013, 117, 15894; K. Matsuda, K. Higashiguchi, in Supramolecular Soft Matter: Applications in Materials and Organic Electronics, (Ed: T. Nakanishi), John Wiley \& Sons, Inc., Hoboken, New Jersey 2011, 215. 


\section{WILEY-VCH}

[40] S.-Z. Pu, F.-S. Zhang, F. Sun, R.-J. Wang, Z.-H. Zhou, S.-K. Chan, Tetrahedron Letters 2003, 44, 1011.

[41] S. Hiroto, K. Suzuki, H. Kamiya, H. Shinokubo, Chemical Communications 2011, 47, 7149; S. Kawamorita, H. Ohmiya, M. Sawamura, Journal of Organic Chemistry 2010, 75, 3855. 


\section{WILEY-VCH}

Dynamic light-activated carbon capture and release in Porous Aromatic Framework-1 is achieved by successfully loading DArE as a guest molecule. Up to $26 \mathrm{wt} \% \mathrm{CO} 2$ desorption capacity is possible with 50wt\% DArE loading. The observed photodynamicity is due to hostguest competition between $\mathbf{D A r E}$ and $\mathrm{CO}_{2}$ inside the sterically hindered pores of PAF-1.

\section{Carbon Capture}

Richelle Lyndon, Kristina Konstas, Daniel J. Keddie, Matthew R. Hill* and Bradley P. Ladewig*

Tunable Photodynamic Switching of DArE@PAF-1 for Carbon Capture

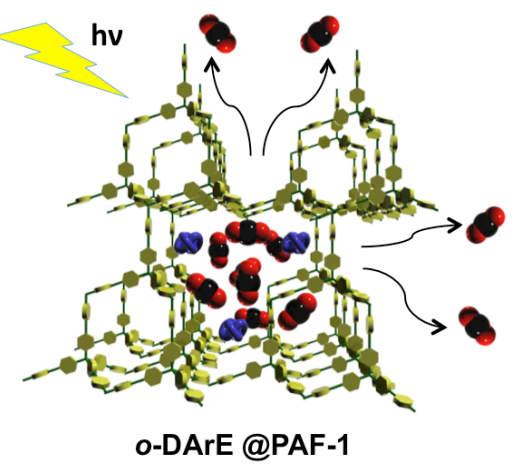

